Editor's Note: These short reviews of recent JNeurosci articles, written exclusively by students or postdoctoral fellows, summarize the important findings of the paper and provide additional insight and commentary. If the authors of the highlighted article have written a response to the Journal Club, the response can be found by viewing the Journal Club at www.jneurosci.org. For more information on the format, review process, and purpose of Journal Club articles, please see http://jneurosci.org/content/ preparing-manuscript\#journalclub.

\title{
A Repulsive Environment Induces Neurodegeneration of Midbrain Dopaminergic Neurons
}

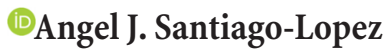 \\ Interdisciplinary Bioengineering Graduate Program and School of Chemical and Biomolecular Engineering, Georgia Institute of Technology, Atlanta, \\ Georgia 30332 \\ Review of Korecka et al.
}

The motor impairments in Parkinson's disease (PD) are caused mainly by the progressive loss of dopaminergic neurons in the substantia nigra par compacta $(\mathrm{SNpc})$. The SNpc extends axons to the dorsal striatum, forming the nigrostriatal pathway, which is involved in motor function. In PD, degeneration of these axons and the consequent loss of dopaminergic input to the striatum alter activity patterns in basal ganglia circuits. This loss precedes motor symptoms (Cheng et al., 2010; Dijkstra et al., 2015; Tagliaferro and Burke, 2016). Although pharmacological dopamine replacement therapy remains the standard treatment for PD, it does not prevent progression of the disease. Efforts to halt this progression have instead focused on targets, such as protein misfolding and aggregation, oxidative stress-induced apoptosis, and neuroinflammation.

Received Oct. 24, 2017; revised Dec. 18, 2017; accepted Dec. 21, 2017.

This work was supported in part by the National Science Foundation Graduate Research Fellowship DGE-1650044. A.J.S.-L. thanks Dr. Robert E. Gross and Dr. Claire-Anne Gutekunst for their ongoing support and guidance.

The authors declare no competing financial interests.

Correspondence should be addressed to Angel J. Santiago-Lopez, Emory University Department of Neurosurgery, Woodruff Memorial Research Building, 101 Woodruff Circle, Suite 6337, Atlanta, GA 30322. E-mail: angel.stgolopez@gatech.edu.

DOI:10.1523/JNEUROSCI.3070-17.2017

Copyright $\odot 2018$ the authors $\quad 0270-6474 / 18 / 381323-03 \$ 15.00 / 0$
Recently, axon guidance molecules have emerged as potential contributors to neurodegeneration in several conditions, including PD (Van Battum et al., 2015). One such molecule is repulsive guidance molecule a (RGMa), a cell-membraneassociated glycosylphosphatidylinositolanchored glycoprotein that interacts with its receptor neogenenin to mediate repulsive axonal guidance and regulate neuron survival (Matsunaga et al., 2004; Itokazu et al., 2012). In previous work, transcriptional profiling revealed that RGMa levels were twofold higher in the SNpc of PD patients than in controls (Bossers et al., 2009). In a recent study published in The Journal of Neuroscience, in situ hybridization analysis of $\mathrm{SN}$ tissue from $\mathrm{PD}$ patients and age-matched controls revealed that RGMa expression was restricted to dopaminergic neurons (Korecka et al., 2017). These results motivated the authors to further investigate the role of RGMa with respect to dopaminergic neurons in the nigrostriatal pathway.

To elucidate whether overexpression of RGMa in the SN alone could induce PD-like neurodegeneration, Korecka et al. (2017) injected adeno-associated viral vectors (AAVs) encoding mouse RGMa under the control of the human synapsin-1 promoter (AAV-RGMa) into the SN of mice. Intranigral administration of AAV-RGMa resulted in RGMa expression in both the SN and the striatum, which is consistent with an anterograde transport of RGMa along nigrostriatal projections. AAV-RGMa overexpression reduced the number of tyrosine hydroxylase-expressing $\left(\mathrm{TH}^{+}\right)$, presumably dopaminergic, neurons in the SNpc by $38 \%-40 \%$ and induced significant motor impairments over the subsequent $\sim 19$ weeks. Importantly, numbers of non- $\mathrm{TH}^{+}$ neurons remained unaltered after AAVRGMa administration, suggesting that the effect was specific to dopaminergic neurons. Moreover, the effects were comparable with those produced in rodent models of PD involving injection of the dopamine-neuronspecific neurotoxin 6-hydroxydopamine or viral delivery of PD-linked mutant $\alpha$-synuclein (Alvarez-fischer et al., 2008; Ip et al., 2017).

Interestingly, when AAV-RGMa was injected bilaterally, the decrease in the number of $\mathrm{TH}^{+}$neurons was accompanied by an increase in $\mathrm{TH}$ expression in the remaining neurons. While an increase in $\mathrm{TH}$ expression following an insult might be indicative of a compensatory mechanism, it does not necessarily translate into the restoration of dopamine signaling along the nigrostriatal pathway. Indeed, the authors detected no such compensatory increase in $\mathrm{TH}$ expression in the striatum after high-dose AAVRGMa administration (Korecka et al., 2017, their Fig. 6B-E), supporting the hy- 
pothesis that loss of striatal dopamine underlies the observed motor deficits. In face of these results, one can hypothesize that overexpression of RGMa leads to a "dieback" or retrograde axonal degeneration, which prevents any compensatory mechanism from countering disease progression. This would be consistent with the observed increase in levels of RGMa in the striatum after the administration of both high- and low-titer dosages of AAVRGMa because this RGMa could act locally to induce axon retraction.

Korecka et al. (2017) also sought to address the role of RGMa in neuroinflammation, a strong component of the pathophysiology of PD. Reactive gliosis, as identified by levels of the ionizing calcium-binding adaptor molecule 1 (expressed in reactive microglia) and GFAP (expressed in reactive astrocytes), was significantly increased in the SNpc after both high- and low-titer AVV-RGMa injections compared with injection of control vectors. The glial response elicited by RGMa overexpression is notable because it suggests that RGMa might induce neurodegeneration through glial activation in addition to retraction of striatal terminals.

Whether neuroinflammation is a causative factor in PD or only aggravates neurodegeneration in response to cellautonomous factors (e.g., protein homeostasis dysregulation, mitochondrial dysfunction) is an unresolved question. In the work of Korecka et al. (2017), it is unlikely that the observed neuroinflammatory response is the main mechanism driving dopaminergic neurodegeneration because high- and low-titer AAVRGMa elicited comparable increases in ionizing calcium-binding adaptor molecule 1 and GFAP expression but produced different degrees of motor impairment. Therefore, the results suggest that the glial response is secondary to neuronal dysfunction caused by RGMa overexpression. Future work should address whether exposure to proinflammatory cytokines (e.g., interleukin-1) increases the susceptibility of dopaminergic neurons to RGMa-induced neurodegeneration, as is observed in an LPS-primed 6-hydroxydopamine rat model of PD (Koprich et al., 2008).

The molecular mechanisms by which RGMa promotes neurodegeneration remain unclear. Previous work points to a mechanism in which the prosurvival protein kinase Akt is dephosphorylated in response to RGMa-neogenin binding (Tanabe and Yamashita, 2014). Moreover, evidence from postmortem analysis of brain tissue from PD patients supports the notion that dephosphorylation of Akt is present in PD-like neurodegeneration (Malagelada et al., 2008). Korecka et al. (2017) evaluated the levels of phosphorylated Akt but did not identify significant differences between AAV-RGMa and control-injected animals. Other pathways, however, might be involved in RGMa-induced neurodegeneration. For instance, other known inhibitory factors in the CNS, such as ephrins, Nogo-A, and chondroitin sulfate proteoglycans, converge on the RhoA/ROCK signaling pathway to induce axonal degeneration. RGMa might therefore be acting through this pathway to induce neuropathological changes. Indeed, there is evidence that RGMa induces growth cone collapse and neurite retraction via RhoA GTPase activation (Conrad et al., 2007). The precise mechanism of RGMa-induced RhoA activation involves the recruitment of the RGMa coreceptor Unc5, which associates with the leukemia-associated Rho guanine nucleotide exchange factor to induce RhoA activation and growth cone collapse (Hata et al., 2009). Moreover, RhoA activation has been linked to neuronal apoptosis (Dubreuil et al., 2003; Semenova et al., 2007), and its inhibition has been shown to improve neuron survival and regeneration in vivo (Koch et al., 2014). Thus, it is possible that RGMa overexpression in SN triggers a signaling cascade orchestrated by active RhoA that affects both dopaminergic neuron survival and the integrity of striatal axon terminals.

The identification of potential mechanisms by which RGMa drives dopaminergic cell loss could translate into effective therapeutic interventions in two ways. First, it could lead to enhanced cellreplacement therapies if modulation of RGMa-neogenin signaling facilitates the survival and growth of neural grafts in the PD brain. Second, biotherapeutics (e.g., gene therapy, antibody-directed therapy) modulating RGMa expression could provide neuroprotection in early stages of PD. Consistent with this therapeutic strategy, antibody-mediated inhibition of RGMa has been shown to be neuroprotective in models of stroke (Tassew et al., 2014) and spinal cord injury (Mothe et al., 2017). It will also be valuable to consider the interplay between repulsive axonal guidance molecules, such as RGMa, and other major neuropathological factors contributing to the inhibitory milieu of the PD brain, such as intracellular inclusions containing $\alpha$-synuclein, to further understand the neuropathology of PD and thus identify novel therapeutic targets.

\section{References}

Alvarez-fischer D, Henze C, Strenzke C, Westrich J, Ferger B, Höglinger GU, Oertel WH, Hartmann A (2008) Characterization of the striatal 6-OHDA model of Parkinson's disease in wild type and $\alpha$-synuclein-deleted mice. Exp Neurol 210:182-193. CrossRef Medline

Bossers K, Meerhoff G, Balesar R, van Dongen JW, Kruse CG, Swaab DF, Verhaagen J (2009) Analysis of gene expression in Parkinson's disease: possible involvement of neurotrophic support and axon guidance in dopaminergic cell death. Brain Pathol 19:91-107. CrossRef Medline

Cheng HC, Ulane CM, Burke RE (2010) Clinical progression in Parkinson disease and the neurobiology of axons. Ann Neurol 67:715-725. CrossRef Medline

Conrad S, Genth H, Hofmann F, Just I, Skutella T (2007) Neogenin-RGMa signaling at the growth cone is bone morphogenetic proteinindependent and involves RhoA, ROCK, and PKC. J Biol Chem 282:16423-16433. CrossRef Medline

Dijkstra AA, Ingrassia A, de Menezes RX, van Kesteren RE, Rozemuller AJ, Heutink P, van de Berg WD (2015) Evidence for immune response, axonal dysfunction and reduced endocytosis in the substantia nigra in early stage Parkinson's disease. PLoS One 10:e0128651. CrossRef Medline

Dubreuil CI, Winton MJ, McKerracher L (2003) Rho activation patterns after spinal cord injury and the role of activated Rho in apoptosis in the central nervous system. J Cell Biol 162: 233-243. CrossRef Medline

Hata K, Kaibuchi K, Inagaki S, Yamashita T (2009) Unc5B associates with LARG to mediate the action of repulsive guidance molecule. J Cell Biol 184:737-750. CrossRef Medline

Ip CW, Klaus L-C, Karikari AA, Visanji NP, Brotchie JM, Lang AE, Volkmann J, Koprich JB (2017) AAV1/2-induced overexpression of A53T- $\alpha$-synuclein in the substantia nigra results in degeneration of the nigrostriatal system with Lewy-like pathology and motor impairment: a new mouse model for Parkinson's disease. Acta Neuropathol Commun 5:11. CrossRef Medline

Itokazu T, Fujita Y, Takahashi R, Yamashita T (2012) Identification of the neogeninbinding site on the repulsive guidance molecule A. PLoS One 7:1-6. CrossRef Medline

Koch JC, Tönges L, Michel U, Bähr M, Lingor P (2014) Viral vector-mediated downregulation of RhoA increases survival and axonal regeneration of retinal ganglion cells. Front Cell Neurosci 8:273. CrossRef Medline

Koprich JB, Reske-Nielsen C, Mithal P, Isacson O (2008) Neuroinflammation mediated by IL- $1 \beta$ increases susceptibility of dopamine neurons to degeneration in an animal model of Parkinson's disease. J Neuroinflammation 5:8. CrossRef Medline

Korecka JA, Moloney EB, Eggers R, Hobo B, Scheffer S, Ras-Verloop N, Pasterkamp RJ, 
Swaab DF, Smit AB, van Kesteren RE, Bossers K, Verhaagen J (2017) Repulsive guidance molecule a (RGMa) induces neuropathological and behavioral changes that closely resemble Parkinson's disease. J Neurosci 37: 9361-9379. CrossRef Medline

Malagelada C, Jin ZH, Greene LA (2008) RTP801 is induced in Parkinson's disease and mediates neuron death by inhibiting Akt phosphorylation/activation. J Neurosci 28: 14363-14371. CrossRef Medline

Matsunaga E, Tauszig-Delamasure S, Monnier PP, Mueller BK, Strittmatter SM, Mehlen P, Chédotal A (2004) RGM and its receptor neogenin regulate neuronal survival. Nat Cell Biol 6:749-755. CrossRef Medline
Mothe AJ, Tassew NG, Shabanzadeh AP, Penheiro R, Vigouroux RJ, Huang L, Grinnell C, Cui YF, Fung E, Monnier PP, Mueller BK, Tator CH (2017) RGMa inhibition with human monoclonal antibodies promotes regeneration, plasticity and repair, and attenuates neuropathic pain after spinal cord injury. Sci Rep 7:10529. CrossRef Medline

Semenova MM, Mäki-Hokkonen AM, Cao J, Komarovski V, Forsberg KM, Koistinaho M, Coffey ET, Courtney MJ (2007) Rho mediates calcium-dependent activation of p38alpha and subsequent excitotoxic cell death. Nat Neurosci 10:436-443. CrossRef Medline

Tagliaferro P, Burke RE (2016) Retrograde ax- onal degeneration in Parkinson disease. J Parkinsons Dis 6:1-15. CrossRef Medline

Tanabe S, Yamashita T (2014) Repulsive guidance molecule-a is involved in Th17-cellinduced neurodegeneration in autoimmune encephalomyelitis. Cell Rep 9:1459-1470. CrossRef Medline

Tassew NG, Mothe AJ, Shabanzadeh AP, Banerjee P, Koeberle PD, Bremner R, Tator CH, Monnier PP (2014) Modifying lipid rafts promotes regeneration and functional recovery. Cell Rep 8:1146-1159. CrossRef Medline

Van Battum EY, Brignani S, Pasterkamp RJ (2015) Axon guidance proteins in neurological disorders. Lancet Neurol 14:532-546. CrossRef Medline 